\title{
PRODUÇÃO DE DOCUMENTAÇÃO ORAL E PRESERVAÇÃO DA MEMÓRIA DO COLÉGIO DE APLICAÇÃO DA UNIVERSIDADE FEDERAL DE SERGIPE
}

Joaquim Tavares da Conceição

Universidade Federal de Sergipe joaquimcodapufs@gmail.com

Rísia Rodrigues Silva Monteiro Universidade Federal de Sergipe risiarodrigues@destaquenoticias.com

Rafaela Cravo de Melo Universidade Federal de Sergipe rafaelacravomelo@gmail.com

\section{RESUMO}

Este artigo apresenta uma discussão a respeito de procedimentos e resultados da composição de um "banco de histórias" formado por narrativas de professores que exerceram a docência no Colégio de Aplicação da Universidade Federal de Sergipe entre os anos de 1959 a 1995. A pesquisa recorreu à metodologia da história oral, acompanhada da reflexão sobre produção de fontes, memória e ações preservacionistas do patrimônio histórico educativo. Foram coletadas e gravadas 26 entrevistas em formato audiovisual transformados em documentos do acervo do Centro de Pesquisa, Documentação e Memória do Colégio de Aplicação, contribuindo para salvaguardar a memória institucional e subsidiar o desenvolvimento de pesquisas e de ações educativas.

Palavras-chave: Banco de histórias. Colégio de Aplicação. Memória.

\section{PRODUCTION OF ORAL DOCUMENTATION AND PRESERVATION OF THE MEMORY OF THE COLÉGIO DE APLICAÇÃO DA UNIVERSIDADE FEDERAL DE SERGIPE}

\begin{abstract}
This article presents a discussion about the results of the composition of a "History bank" which is formed by narratives from teachers that taught in Colégio de Aplicação da Universidade Federal de Sergipe, between 1959 and 1995. The research resorted to the oral history methodology, followed by a reflection about the production of preservationist sources, memories and actions from the educative historic heritage. 26 audiovisual interviews were collected and recorded and then turned into documents of the collection of the Research Documentation and Memory Center of Colégio de Aplicação, therefore, contributing to safeguard the institutional memory and promote the development of educative actions and researches.
\end{abstract}

Keywords: History bank. Colégio de Aplicação. Memory.

PRODUCCIÓN DE DOCUMENTACIÓN ORAL Y LA PRESERVACIÓN DE LA MEMORIA DE LA MEMORIA DEL COLÉGIO DE APLICAÇÃO DA UNIVERSIDADE FEDERAL DE SERGIPE 


\section{RESUMEN}

Este artículo presenta una discusión sobre procedimientos y resultados de la composición de un "banco de historias" formado por narraciones de profesores que enseñaron en el Colégio de Aplicação de la Universidade Federal de Sergipe entre los años de 1959 y 1995. La investigación ha seguido la metodología de la historia oral, acompañada de la reflexión sobre producción de fuentes, memoria y acciones preservacionistas del patrimonio histórico educativo. Fueron colectadas y grabadas 26 entrevistas en formato audiovisual transformados en documentos del acervo del Centro de Investigación, Documentación y Memoria do Colégio de Aplicação, contribuyendo para salvaguardar la memoria institucional y subvencionar el desarrollo de investigaciones y de acciones educativas.

Palabras-clave: Banco de historias. Colégio de Aplicação. Memoria.

\section{PRODUCTION DE DOCUMENTATION ORALE ET LA PRÉSERVATION DE LA MÉMOIRE DU COLÉGIO DE APLICAÇÃO DA UNIVERSIDADE FEDERAL DE SERGIPE}

\section{RÉSUMÉ}

Cet article présente une discussion sur les procédures et les résultats de la composition d'une «banque d'histoires» composé par les récits de professeurs qui ont enseigné au Colégio de Aplicação de l'Université fédérale de Sergipe entre 1959 et 1995. La recherche a utilisé la méthodologie de l'histoire orale, accompagnée d'une réflexion sur la production de sources, mémoire et les actions conservatrices du patrimoine historique éducatif. On a recueilli et enregistré 26 entretiens en audiovisuel et on les a transformés en documents pour le fonds du Centre de Recherche, Documentation et de Mémoire du Colégio de Aplicação, en contribuant pour préserver la mémoire institutionnelle et subventionner le développement de recherche et d'actions éducatives.

Mot-clés: Banque d'histoire. Colégio de Aplicação. Mémoire.

\section{INTRODUÇÃO}

Este artigo apresenta uma discussão a respeito da produção e de resultados da composição de um "banco de histórias"1 formado por narrativas de professores que exerceram a docência no Colégio de Aplicação da Universidade Federal de Sergipe. O objetivo principal que moveu a pesquisa foi "gerar documentos novos" compondo um banco de entrevistas para

\footnotetext{
1 Projeto Composição de "banco de histórias" do Colégio de Aplicação (UFS). Combater "silêncios" e "esquecimentos" e preservar a memória institucional. Pibic/CNPq/UFS. O projeto foi executado por uma equipe formada por estudantes de iniciação científica e por doutorandos, mestrandos e graduandos membros do Grupo de Estudos e Pesquisas em História da Educação: Memórias, sujeitos, saberes e práticas educativas (GEPHED/CNPq/UFS), cadastrados na equipe executora do projeto. Também contou com o apoio do Núcleo de Editoração e Audiovisual (NEAV/UFS) e do Departamento de Comunicação Social (DCOS/UFS).
} 
a preservação da memória e a produção de documentação para futuras pesquisas - condição fim do banco de histórias (MEIHY; RIBEIRO, 2011).

A constituição do "banco de histórias" correspondeu ao período de 1959, ano da fundação do Ginásio de Aplicação da Faculdade Católica de Filosofia de Sergipe, até 1995, ano em que o colégio, já incorporado à Universidade Federal de Sergipe, passou a funcionar em prédio próprio localizado na Cidade Universitária prof. José Aloísio de Campos.

O termo "banco de histórias" é empregado no sentido de banco de memórias ou:

[...] conjunto de gravações que se orientam segundo relatos de grupos atentos à própria presença em contextos sociais ou institucionais, como: migrantes, emigrantes, grupos profissionais, agremiações de manifestações de determinada causa, escolas, empresas, setores profissionais ou de lazer ou ainda participantes de determinado evento circunstancial como campanha ou testemunho. (MEIHY; RIBEIRO, 2011, p. 14).

O "banco de histórias" integra a documentação audiovisual do Centro de Pesquisa, Documentação e Memória do Colégio de Aplicação da Universidade Federal de Sergipe (Cemdap). O Cemdap surgiu a partir de atividades desenvolvidas em projetos de pesquisa que tiveram como objetivo a produção de um acervo de documentos produzidos nos anos de existência do Colégio de Aplicação da Universidade Federal de Sergipe. Como resultados desses projetos, o Cemdap foi instalado em sala específica do prédio escolar, onde a documentação coletada encontra-se acondicionada em pacotilhas, guardadas em armários, além de contar com uma coleção de objetos da cultura material (CONCEIÇÃO; NOGUEIRA, 2018).

A preservação de acervos documentais, orais e/ou audiovisuais e de objetos da cultura material tem permitido o levantamento de questionamentos e a produção de compreensões a respeito das funções, atividades, sujeitos da ação educativa, dentre outros aspectos da história e cultura escolar de diversas instituições educativas. Além disso, as pesquisas têm resultado na organização e/ou instalação e funcionamento de centros de memória e arquivos de preservação do patrimônio educativo (ALVES, 2005; CARDOSO, 2014; MENEZES, 2011; SIMSON, 2000; ZAIA, 2005). Por conseguinte, as ações de preservação de documentos permanentes conjuntos documentais custodiados em caráter definitivo em função do seu valor histórico e científico (BELLOTTO, 1991) - e objetos da cultura material reunidos no Cemdap, recebendo as contribuições dessas pesquisas, também se inserem na perspectiva de preservação do 
patrimônio educativo e da produção de compreensões ${ }^{2}$ a respeito da trajetória institucional (CONCEIÇÃO, 2016a, 2016b).

O Cemdap igualmente tem proporcionado o desenvolvimento de atividades de ensino, especialmente na perspectiva da educação patrimonial (HORTA, GRUNBERG, MONTEIRO 1999), e o desenvolvimento de projetos de iniciação científica com o envolvimento de estudantes da educação básica e da graduação.

\section{COMPOSIÇÃO DE INFORMAÇÕES DA TRAJETÓRIA DO COLÉGIO DE APLICAÇÃO-UFS}

A origem do Colégio de Aplicação ${ }^{3}$ da Universidade Federal de Sergipe está relacionada com a existência da Faculdade Católica de Filosofia de Sergipe, fundada no ano de 1950, com o objetivo de formar professores para atuarem no ensino secundário e normal. Em 30 de junho de 1959, por procuração de Dom José Vicente Távora, bispo da Diocese de Aracaju e presidente da Sociedade Sergipana de Cultura - sociedade pertencente à Arquidiocese de Aracaju -, o monsenhor Luciano José Cabral Duarte fundou o Ginásio de Aplicação, com a finalidade de que o estabelecimento servisse como escola-laboratório para práticas didáticas e pedagógicas, especialmente por meio de estágios desenvolvidos pelos graduandos da faculdade (CEMDAP, 1916; NUNES, 2012).

Figura 1: Dom Luciano José Cabral Duarte - fundador do Ginásio de Aplicação - ministrando aula na Faculdade Católica de Filosofia de Sergipe (195?).

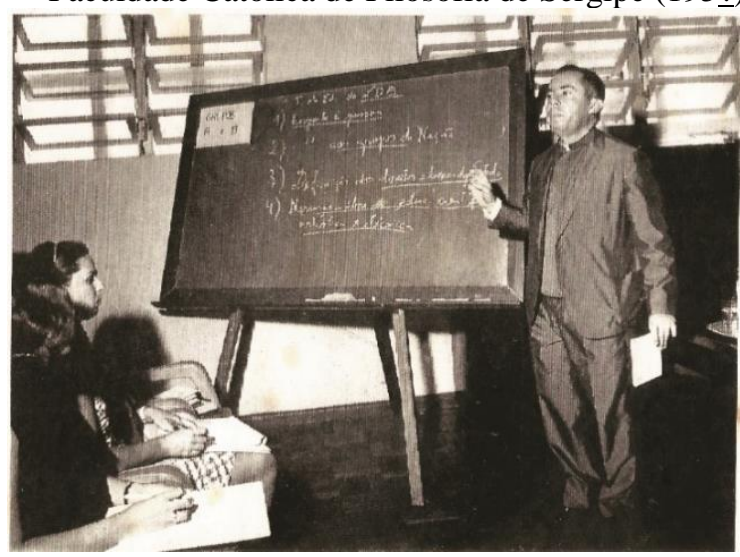

Fonte: Acervo do Cemdap - doação do Instituto Dom Luciano Duarte (IDLD).

\footnotetext{
${ }^{2}$ Nesse sentido, podem ser citadas dissertações de mestrado defendidas no Programa de Pós-Graduação em Educação, na linha História da Educação, a saber: "Um olhar sobre a história da organização curricular da educação física no Colégio de Aplicação da Universidade Federal de Sergipe (1959-1996)" (GUIMARÃES, 2016) e "Flagrando a Vida": Trajetória de Lígia Pina. Professora, literata e acadêmica (1925-2014) (MARTIRES, 2016). ${ }^{3}$ Os colégios de aplicação constituem um tipo especial de escola, criado por força do Decreto-Lei $\mathrm{n}^{\circ} 9.053$, de 12 de março de 1946, que determinava que as "[...] Faculdades de Filosofia federais, reconhecidas ou autorizadas a funcionar no território nacional, ficam obrigadas a manter um ginásio de aplicação destinado à prática docente dos alunos matriculados no curso de didática" (BRASIL, 1946).
} 
Em 7 de julho de 1959, após o processo de verificação prévia, o Ginásio de Aplicação foi autorizado a funcionar pela Diretoria do Ensino Secundário do Ministério da Educação e Cultura - Inspetoria Seccional de Aracaju. O estabelecimento iniciou suas atividades com 30 alunos matriculados na $1^{\text {a }}$ série do primeiro ciclo do ensino secundário (curso ginasial), sob a direção da professora Rosália Bispo dos Santos (CEMDAP, 1916; NUNES, 2012). Em 30 de dezembro de 1965, o Ginásio de Aplicação passou a ser denominado de Colégio de Aplicação em decorrência da autorização para oferecer o curso colegial - segundo ciclo do antigo ensino secundário (BRASIL, 1942).

Figura 2: Rosália Bispo dos Santos - primeira diretora do Ginásio de Aplicação (1960).

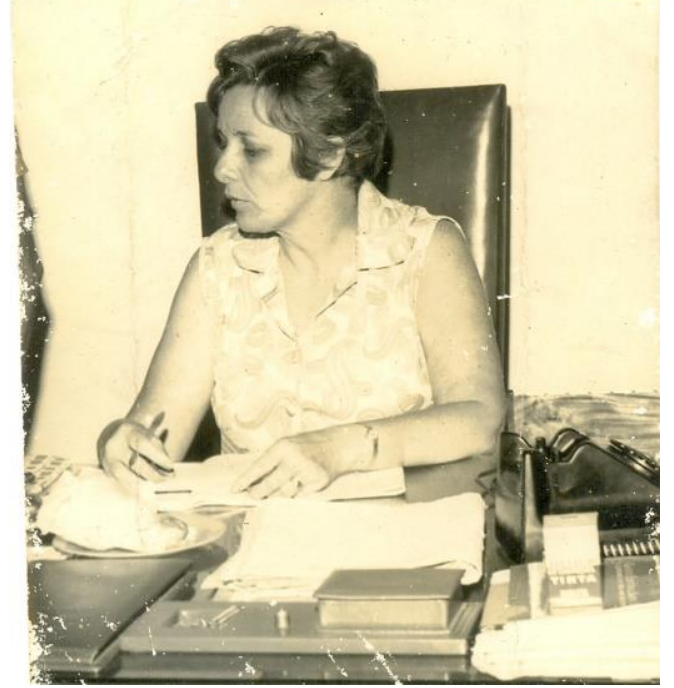

Fonte: Acervo do Cemdap.

Com a criação da Universidade Federal de Sergipe (UFS), a Faculdade de Filosofia e o Colégio de Aplicação, que dela era parte integrante, foram incorporados à Fundação Universidade Federal de Sergipe (BRASIL, 1967). Inserido na estrutura da Universidade, o Colégio de Aplicação (Codap) passou a ser um órgão suplementar, ligado diretamente à reitoria. Além de permanecer exercendo as funções de ensino e de campo para a execução de estágios curriculares, o colégio também passou a desenvolver atividades de pesquisa e extensão.

Desde a sua fundação em 1959, o Colégio de Aplicação funcionou na cidade de Aracaju, instalado no prédio da Faculdade Católica de Filosofia de Sergipe, juntamente com cursos superiores oferecidos pela faculdade. No ano de 1981, o colégio passou a funcionar na Cidade Universitária Prof. José Aloísio de Campos, instalado em salas do pavimento superior do prédio denominado de Didática III e, a partir do ano de 1995, foi instalado em prédio originalmente construído para o seu funcionamento. 
Figura 3: Formandas do Curso Colegial - Colégio de Aplicação da UFS (1971).

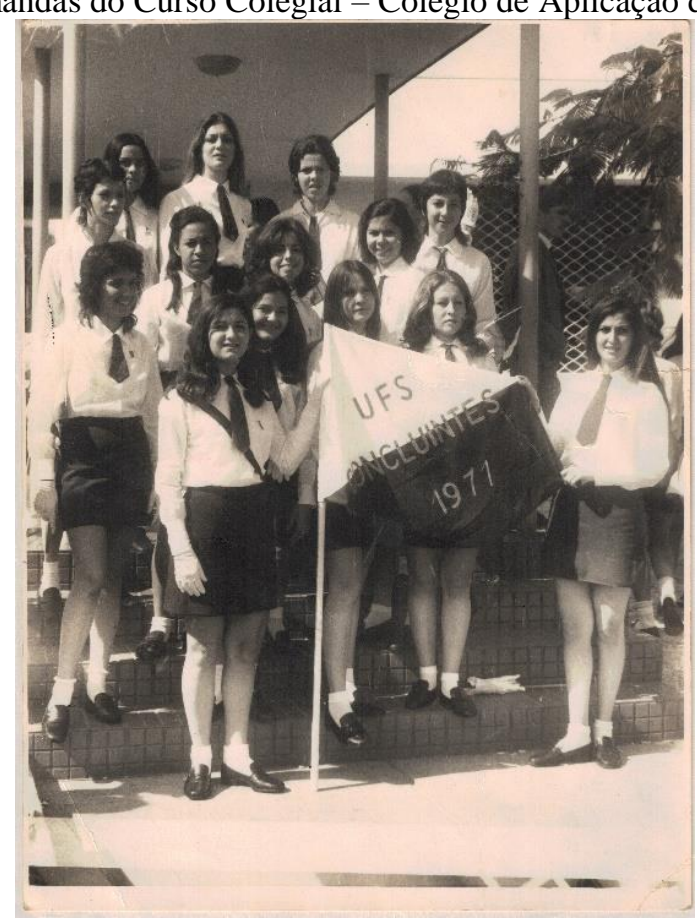

Fonte: Acervo do Cemdap.

Enquanto pertenceu à Sociedade Sergipana de Cultura e esteve vinculado à Faculdade Católica de Filosofia de Sergipe, o estabelecimento cobrava mensalidade de seus alunos. De 1960, quando recebeu a primeira turma, até a década de 1970, o ingresso de alunos na série inicial ocorria por meio de sistema seletivo com aplicação de provas de conhecimentos matemáticos e de língua portuguesa. Na década de 1970, o ingresso passou a ser por meio de sorteio. Já no início da década de 1980, o estabelecimento voltou a adotar o sistema seletivo com provas de conhecimento. E, em 2009, foi aprovado o ingresso de alunos por meio de sorteio público de vagas.

Nos anos de existência do Colégio de Aplicação - marcada por mudanças de denominação, de local de funcionamento e de desempenho de diferentes atividades - diversos agentes da ação educativa contribuíram para a existência e configuração do colégio e, por conseguinte, são "guardiões da memória" (NORA, 1993) institucional. Assim, a pesquisa contou com professores(as) que contribuíram, na condição de narradores(as)/colaboradores(as), para a preservação da memória por meio da "doação" de seus relatos orais, que passaram a compor o acervo de documentação audiovisual do Cemdap.

A composição do "banco de histórias" foi movida pela ideia de produzir documentos novos por meio da "recuperação do vivido conforme concebido por quem viveu" (ALBERTI, 2005, p. 23), utilizando critérios qualitativos típicos da metodologia da história oral. A pesquisa dialogou com o entendimento de que trabalhar com "memórias" permite voltar o "olhar" para 
aspectos desconhecidos, resultando em uma "mudança de enfoque, mas também na abertura de novas áreas importantes de investigação" (THOMPSON, 1992, p. 27). Nesse sentido, a utilização da memória contribui para a compreensão da história institucional e da carreira dos professores e estudantes, dos saberes escolares e de outros aspectos do cotidiano escolar e/ou da cultura escolar e também para ouvir personagens muitas vezes silenciados nos documentos tradicionalmente utilizados na pesquisa historiográfica (NORA, 1993).

Além de responder novas questões investigativas e combater o silêncio e/ou esquecimentos, a produção e guarda de documentos orais é também uma forma de garantir a preservação do patrimônio educativo escolar, igualmente evitando as perdas relacionadas com novas formas de armazenamento de informações do mundo tecnológico e/ou digital (LE GOFF, 1992). Assim, os produtos das entrevistas foram transformados em documentos de suporte preservacionista (BOMENY, 1995; FERNANDES, 2015).

\section{PROCEDIMENTOS METODOLÓGICOS PARA A COMPOSIÇÃO DO BANCO DE HISTÓRIAS DO CENTRO DE MEMÓRIA DO COLÉGIO DE APLIAÇÃO-UFS}

A finalidade principal dos centros de memória e/ou memoriais é reunir, organizar, guardar para fins de preservação, de atividades pedagógicas e de pesquisas, conjuntos documentais e/ou objetos de valor histórico, científico ou de outro caráter cultural. Contudo, um centro de memória também atua como espaço de produção de novos conteúdos a respeito da memória e história da instituição e de outros temas correlatos (CENTRO DE MEMÓRIA..., 2013; TESSITORE, 2003). Seguindo a tendência de outros centros de preservação de documentação, especialmente da documentação e memória de instituições educativas (CARVALHO; RIBEIRO, 2014), o desenvolvimento da pesquisa produziu informações para a compreensão da trajetória institucional, levando em conta o entendimento e metodologia da "história oral instrumental", que

[...] cumpre suas funções no registro, trabalho de captação das entrevistas e da passagem do oral para o escrito, no arquivamento e disponibilidade pública, de acordo com acertos prévios entre as partes. [...] A história oral instrumental deve ser entendida como uma parte independente de futuras investidas. Estas podem ou não ocorrer dependendo das possibilidades complementares ou de projetos feitos por outras pessoas usando essa base. (MEIHY; RIBEIRO, 2011, p. 15).

O uso da história oral, no contexto de uma instituição escolar, é uma atividade possível de ser executada com sujeitos que tenham testemunhado ou participado de diversas formas e 
em momentos distintos da existência da escola. Os relatos coletados apresentam uma dimensão importante, que é a sua condição de fonte e a potencialidade para o desenvolvimento de diversos tipos de pesquisas e/ou questionamentos futuros. Portanto, a produção do material levou em conta a condição meio do banco de histórias:

\begin{abstract}
Normalmente a documentação resultante da gravação de entrevistas é arquivada com duplo objetivo: jurídico e de acervo, para que eventualmente, no futuro, sejam feitos estudos sobre a história da instituição. Assim, caso as entrevistas gravadas para banco de histórias sejam aproveitadas mais tarde por outros pesquisadores, a condição fim para a situação de banco de histórias permanece inalterada, mas se transforma em meio para os pesquisadores que venham fazer uso delas. Se o projeto previr mais do que o banco de história ou registros arquivados de experiências, se supõe análises imediatas e articuladas pelo grupo que o executa, o conjunto de entrevistas funciona como meio e não como fim. Se, contudo, a série de entrevistas for destacada da análise e usada como acervo, torna-se fim. (MEIHY; RIBEIRO, 2011, p. 14).
\end{abstract}

As "memórias" foram coletadas através da técnica da entrevista com a utilização de um roteiro temático, confeccionado a partir das evidências históricas preliminarmente encontradas em documentos escritos ou em depoimentos anteriores. Levou-se em consideração que o grupo é suporte da memória, pois ela é coletiva, mas é o indivíduo que recorda. Cada grupo vive o tempo de forma diferente, como o tempo vivido no espaço escolar. Assim, por muito que se “[...] deva à memória coletiva, é o indivíduo que recorda. Ele é o memorizador e das camadas do passado a que tem acesso pode tecer objetos que são, para ele, e só para ele, significativos dentro de um tesouro comum" (BOSI, 1994, p. 411). Igualmente, com relação às memórias, é importante considerar que:

\begin{abstract}
A memória é a vida, sempre carregada por grupos vivos e, nesse sentido, ela está em permanente evolução, aberta à dialética da lembrança do esquecimento, inconsciente de suas deformações sucessivas, vulnerável a todos os usos e manipulações, suscetível de longas latências e repentinas revitalizações [...] A memória é um fenômeno sempre atual, um elo vivido no eterno presente [...] A memória emerge de um grupo que ela une, o que quer dizer, como Halbwachs o fez, que há tantas memórias quantos grupos existam; que ela é de natureza, múltipla e desacelerada, coletiva, plural e individualizada. (NORA, 1993, p. 7).
\end{abstract}

A opção foi pelo gênero de "história oral temática", que se mostrou adequada ao objetivo de produção do banco de histórias do Colégio de Aplicação da Universidade Federal de Sergipe, ou seja, "[...] a existência de um foco central que justifica o ato da entrevista em um projeto, recorta e conduz a possíveis maiores objetividades. Por lógico reconhece-se que objetividade absoluta não existe, mas há recursos capazes de limitar devaneios e variações" (MEIHY; HOLANDA, 2013, p. 35). Pautou-se também por questões teóricas que envolvem memória e história (NORA, 1993), os sentidos e disputas da memória, a função do "não-dito", 
os esquecimentos e a formação de identidades proporcionada pela rememoração (BOSI, 1994; POLLAK, 1989, 1992).

Os levantamentos ocorreram com sujeitos que mantiveram relações com o Colégio de Aplicação no período de 1959 a 1995, conforme especificado anteriormente, desenvolvendo-se atividades de investigação apresentadas no quadro em sequência:

Quadro 1. Etapas/Atividades para a constituição de documentação audiovisual do Centro de Memória Pesquisa e Documentação do Colégio de Aplicação (Cemdap) - coleta de relatos orais de professores(as) (1959-1995).

\begin{tabular}{|l|l|}
\hline $\mathbf{N}^{\mathbf{0}}$ & \multicolumn{1}{|c|}{ Etapas/Atividades realizadas } \\
\hline 01 & $\begin{array}{l}\text { Produção de informações a respeito da história e perfil de professores(as) egressos do Colégio } \\
\text { de Aplicação }\end{array}$ \\
\hline 02 & $\begin{array}{l}\text { Realização de levantamentos bibliográficos a respeito de técnicas da história oral e de bancos } \\
\text { de documentação audiovisual; }\end{array}$ \\
\hline 03 & Qualificação dos principais problemas/assuntos a serem abordados \\
\hline 04 & Produção de roteiros de entrevistas levando em conta as informações coletadas \\
\hline 05 & $\begin{array}{l}\text { Identificação e construção de uma amostra de professores(as) egressos potenciais } \\
\text { entrevistados (narradores(as)/colaboradores(as) }\end{array}$ \\
\hline 06 & Coleta dos relatos orais (gravação de entrevistas) \\
\hline 07 & Arquivamento do material para posterior trabalho de edição \\
\hline
\end{tabular}

Fonte: Projeto Composição de "banco de histórias" do Colégio de Aplicação (UFS). Combater "silêncios" e "esquecimentos" e preservar a memória institucional (Pibic/CNPq/UFS).

O levantamento de fontes e produção de informações a respeito da história do Colégio de Aplicação por meio de pesquisa documental e de pesquisa bibliográfica foram realizados no acervo documental do Centro de Pesquisa, Documentação e Memória do Colégio de Aplicação/UFS. As informações levantadas possibilitaram a identificação de professores(as) egressos para a constituição de um rol de potenciais entrevistados. A partir desse levantamento, constituiu-se a amostra de entrevistados(as) buscando a participação de docentes que exerceram o magistério no Colégio de Aplicação em diferentes fases ou gerações significativas na trajetória institucional, a saber: a) Primeira fase: de 1959 a 1968 -etapa da fundação do Ginásio de Aplicação da Faculdade Católica de Filosofia de Sergipe (instituição privada) até a incorporação da faculdade e do ginásio na estrutura da Universidade Federal de Sergipe; b) Segunda fase: 1969 a 1981 - funcionamento do Colégio de Aplicação na estrutura da universidade no antigo prédio da Faculdade de Filosofia em Aracaju; c) Terceira fase: 1982 a 1995 - transferência e funcionamento do Colégio de Aplicação para a Cidade Universitária Prof. José Aloísio de Campos (São Cristóvão-SE), instalado em salas do prédio denominado de Didática III, até a inauguração e funcionamento do Colégio de Aplicação em prédio próprio.

Inicialmente, a previsão era de que no período de 1 (um) ano fosse obtido um banco com 40 (quarenta) entrevistas gravadas em formato audiovisual, sendo 10 (dez) para cada fase 
acima especificada. Quanto à escolha dos entrevistados, além de terem vivenciado uma ou mais fases indicadas, sua atuação na instituição também na condição de diretor(a) foi considerada para a escolha, tendo em vista a potencialidade de informações que poderiam ser captadas. A noção de narradores(as)/colaboradores(as), levando em conta pressupostos da metodologia da história oral utilizados, foi empregada conforme a seguinte compreensão:

\begin{abstract}
No caso da história oral, por acatar eticamente o interlocutor e colocá-lo como centro gerador de visões, por levá-lo em conta além de seu papel de 'fornecedor de dados', de 'transmissor de informações', ou 'testemunho', valoriza-se o conceito de colaboração. Reside aí uma das inovações da história oral mais humanizada. Note-se que a colaboração não iguala as partes, mas convida a um trabalho participante em que os dois polos - os entrevistados e os entrevistadores - são sujeitos ativos, unidos no propósito de produzir um resultado que demanda convivência (MEIHY; RIBEIRO, 2011, p. 23).
\end{abstract}

De modo geral, o roteiro das entrevistas explorou temáticas recorrentes na "memória coletiva" da instituição, com questões gerais e específicas a depender da "geração" dos entrevistados. Em geral, para todos os narradores(as)/colaboradores(as), foram questionadas as seguintes temáticas: a) Formas de ingresso de alunos - seleção por meio de exames/provas; sorteio público; b) Informações a respeito dos agentes educativos que atuaram no colégio (diretores, professores, funcionários); c) Perfil socioeconômico dos alunos nas diversas fases do colégio; d) Configurações e espaços físicos ocupados pelo colégio; e) Aspectos das práticas escolares (professores, disciplinas, exames, festas, práticas disciplinas) e extraescolares; f) Desenvolvimento de estágios supervisionados e outras funções educacionais desenvolvidas no colégio; g) Outros aspectos da cultura escolar, preliminarmente identificados em pesquisa documental. Além dessas questões gerais, foram definidos questionamentos correlatos e específicos, levando em conta a carreira do entrevistado(a) na instituição. A produção do roteiro também considerou as informações coletadas na pesquisa documental e bibliográfica a respeito da história do Colégio de Aplicação e de seus agentes educativos.

Como base para a elaboração do roteiro de entrevista, na fase preparação, foram coletados dados relacionados a data e local de nascimento, filiação, formação escolar; carreira profissional e/ou acadêmica dos narradores(as)/colaboradores(as). Para a gravação das entrevistas, utilizaram-se equipamentos e cinegrafistas cedidos pelo Núcleo de Editoração e Audiovisual (NEAV/UFS). Com exceção de duas entrevistas, realizadas no domicílio de professoras entrevistadas, todas as outras foram feitas em estúdio de gravação do Departamento de Comunicação Social (DCOS/UFS). As imagens a seguir apresentam registros de gravações de entrevistas para o "banco de histórias". 
Figura 4: Registro fotográfico da entrevista com a profa. Maria Hozana de Souza - estúdio de gravação DCOS/UFS (2018).

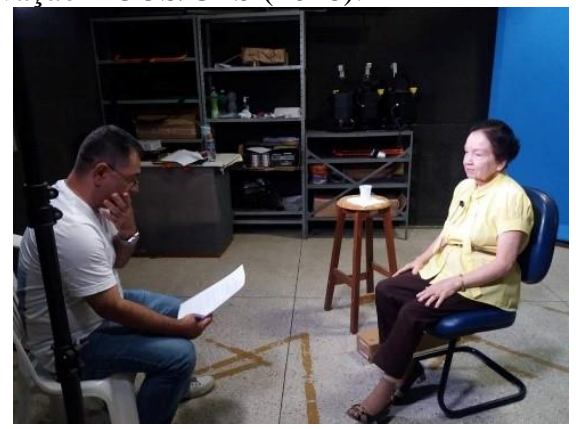

Fonte: Acervo do Cemdap.

Figura 6: Registro fotográfico da entrevista com o prof. Manoel Messias Vasconcelos - estúdio de gravação DCOS/UFS (2017).

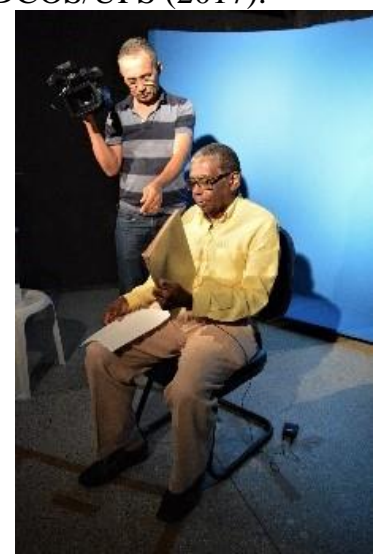

Fonte: Acervo do Cemdap.
Figura 5: Registro fotográfico da entrevista com a profa. Maria de Lourdes Amaral Maciel - residência da entrevistada (2017).

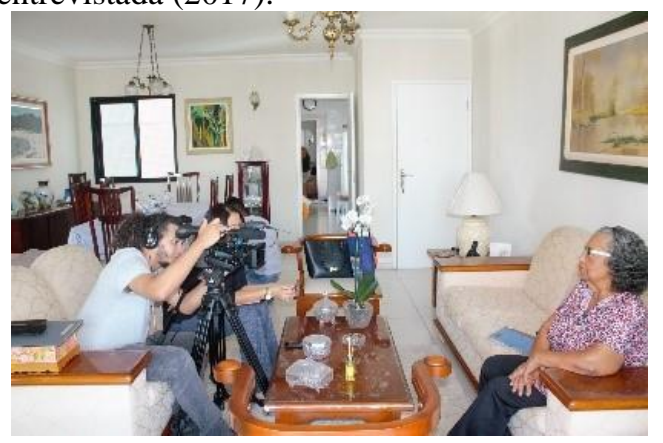

Fonte: Acervo do Cemdap.

Figura 7: Registro fotográfico da entrevista com o profa. Maria Josefa de Menezes Almeida - estúdio de gravação DCOS/UFS (2017).

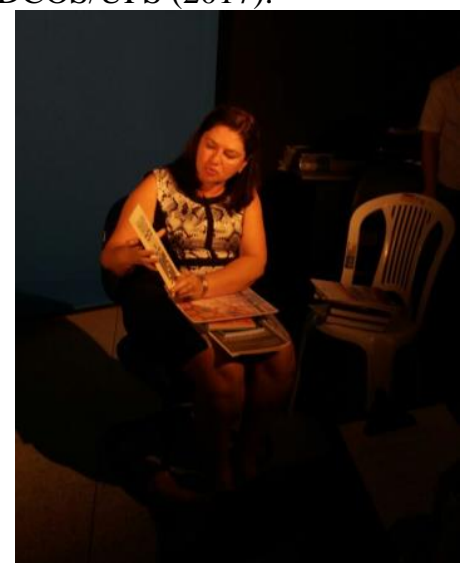

Fonte: Acervo do Cemdap.

A escolha foi por entrevistas únicas, adequada para a finalidade de banco de histórias, com estímulos e registradas em formato audiovisual. Durante a realização das entrevistas, além do suporte audiovisual, foram registradas fotografias dos narradores(as)/colaboradores(as) e equipe e providenciadas as autorizações para a utilização e divulgação das informações e imagens e sons coletados. Com o intuito de envolver os entrevistados com o trabalho de preservação da memória institucional, antes da realização das entrevistas, de acordo com a disponibilidade do entrevistado(a), foi programada uma visita ao Cemdap, momento em que os participantes puderam ter acesso a documentos e objetos da cultura material do colégio, com o intuito de favorecer a "recuperação de lembranças" (BOSI, 1994; POLLAK, 1989, 1992). 
Figura 8: Visita ao Cemdap do prof. Juan José Rivas (entrevistado) - primeiro plano (2018).

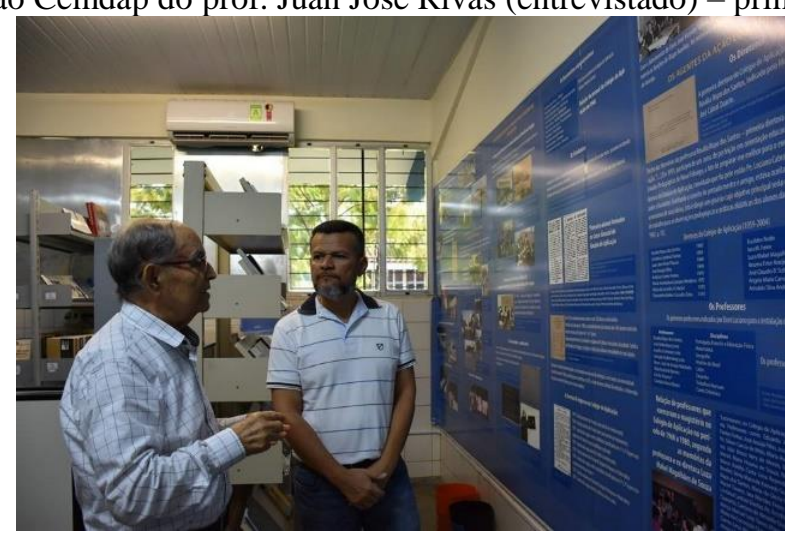

Fonte: Acervo do Cemdap.

O contato com os narradores(as)/colaboradores(as) também foi importante para a prospecção de documentos de acervo pessoal relacionados com a carreira do entrevistado(a) na instituição.

\section{RESULTADOS E PERSPECTIVAS DO BANCO DE HISTÓRIAS CEMDAP}

Por diversas intercorrências, desistência de convidados para participação do projeto, falta de disponibilidade de equipamentos e/ou estúdio de gravação e pessoal, das 40 entrevistas programadas, foram gravadas 26 com professores(as) egressos do Colégio de Aplicação que atuaram na instituição entre o anos de 1960 a 1995. O material coletado encontra-se arquivado em meio digital (HD externo), em processo de construção de informações preliminares para o processo de edição e disponibilização para consulta. O quadro em sequência apresenta a relação das entrevistas gravadas. 
Quadro 2: Relação de entrevistas realizadas (2017-2018).

\begin{tabular}{|c|c|c|c|c|}
\hline $\mathbf{N}^{\mathbf{0}}$ & $\begin{array}{c}\text { Nome do } \\
\text { narrador/colaborador }\end{array}$ & $\begin{array}{c}\text { Data } \\
\text { Nascimento }\end{array}$ & $\begin{array}{c}\text { Ano de } \\
\text { ingresso } \\
\text { na } \\
\text { instituição }\end{array}$ & $\begin{array}{l}\text { Disciplina lecionada e/ou outra atividade } \\
\text { desempenhada na instituição }\end{array}$ \\
\hline 01 & Rosália Bispo dos Santos & 13/04/1924 & 1959 & Francês / diretora (1960 a 1965) \\
\hline $\mathbf{0 2}$ & Ruan José Rivas Páscoa & $19 / 03 / 1933$ & 1960 & Filosofia / diretor (1968 a 1969) \\
\hline 03 & $\begin{array}{l}\text { Therezinha Belém Carvalho } \\
\text { Teles }\end{array}$ & $13 / 11 / 1943$ & 1966 & Francês e Português / diretora (1974 a 1979) \\
\hline 04 & Manoel Messias Vasconcelos & $18 / 10 / 1939$ & 1967 & Desenho e Orientação educacional \\
\hline 05 & Antônio Fontes Freitas & $15 / 11 / 1942$ & 1967 & Matemática / diretor (1970-1972) \\
\hline 06 & José Padilha de Oliveira & $10 / 10 / 1939$ & 1967 & Filosofia, Latim, Religião \\
\hline 07 & Maria Hozana de Souza & $02 / 10 / 1942$ & 1967 & Geografia \\
\hline 08 & Maria de Lourdes A. Maciel & 28/11/1938 & 1968 & História / diretora (1973 a 1974) \\
\hline 09 & $\begin{array}{l}\text { Maria do Carmo L. M. } \\
\text { Mendonça }\end{array}$ & 22/09/1946 & 1968 & Geografia \\
\hline 10 & Cremildes Maria Barbosa Lessa & 23/09/1947 & 1968 & Francês \\
\hline 11 & Iara Mendes Freire & 28/03/1941 & 1969 & Biologia / diretora (1980 a 1990) \\
\hline 12 & Luza Mabel M. de Souza & 20/11/1949 & 1974 & Português / diretora (1990 a 1993) \\
\hline 13 & Luzia Cristina Barreto Oliveira & 23/10/1952 & 1975 & Inglês \\
\hline 14 & Marly Maria Santos Pinto & $04 / 05 / 1955$ & 1980 & Biologia \\
\hline 15 & Maria Inêz Oliveira Araújo & $13 / 01 / 1958$ & 1980 & Biologia e ex-aluna \\
\hline 16 & $\begin{array}{l}\text { Maria de Fatima Evangelista de } \\
\text { Amorim Santos }\end{array}$ & $02 / 07 / 1956$ & 1991 & Desenho e Orientação educacional \\
\hline 17 & Antônia Bezerra Marques & $11 / 06 / 1964$ & 1991 & Inglês / Exerceu atividades administrativas \\
\hline 18 & $\begin{array}{l}\text { Maria Josefa de Menezes } \\
\text { Almeida }\end{array}$ & 26/10/1963 & 1992 & Português \\
\hline 19 & José Genivaldo Martires & $12 / 11 / 1968$ & 1992 & História \\
\hline 20 & Silvania do Nascimento & $16 / 10 / 1964$ & 1992 & História \\
\hline 21 & João Berechans de Oliveira & $10 / 05 / 1954$ & 1993 & Educação Física \\
\hline 22 & Silaine Maria Gomes Borges & 29/07/1957 & 1993 & Pedagoga e Orientação educacional \\
\hline 23 & Vera Lúcia Mesquita Martins & $27 / 04 / 1960$ & 1993 & Português \\
\hline 24 & Adjane da Costa T. e Silva & 20/03/1967 & 1994 & Química \\
\hline 25 & Marcos Antônio da S. Pedroso & 04/08/1960 & 1995 & Desenho \\
\hline 26 & Oneize Amaras de Araújo & $04 / 11 / 1955$ & 1995 & Filosofia \\
\hline
\end{tabular}

Fonte: Quadro elaborado pelos autores.

A prospecção de documentos do acervo pessoal, em momentos pré-entrevista e em conversas durante o processo de realização, também resultou na doação por parte dos narradores(as)/colaboradores(as) de quantidade importante de documentos inseridos no conjunto documental do Cemdap. Entre os materiais doados, encontram-se livros de autoria dos entrevistados, projetos, documentos pessoais, fotografias, dentre outros.

Os resultados dos levantamentos e dos produtos, frutos da pesquisa em questão, apresentam perspectivas importantes: aprimoramento de uma política de preservação e divulgação da memória e do patrimônio imaterial da Universidade Federal de Sergipe; produção de trabalhos científicas a respeito da memória e história do colégio e da universidade; desenvolvimento da educação patrimonial na comunidade escolar; fontes para pesquisas futuras contribuindo para o desenvolvimento da produção historiográfica da educação e continuação da formação e iniciação de estudantes em pesquisa científica; e aprimoramento das atividades de educação patrimonial escolar. 
O processo de edição do material coletado, fase a ser iniciada, proporcionará melhores condições de acessibilidade para a comunidade universitária e pesquisadores interessados no conjunto documental coletado.

\section{CONSIDERAÇÕES FINAIS}

Considerando que o objetivo principal que moveu a pesquisa foi de "gerar documentos novos" compondo um "banco de histórias" para a preservação da memória e a produção de documentação para futuras pesquisas (condição fim do banco de histórias), os resultados foram exitosos e importantes. Nesse sentido, foram coletadas 26 entrevistas gravadas em formato audiovisual, e também a prospecção de documentos do acervo pessoal de colaboradores/narradores participantes da pesquisa.

Nas análises preliminares produzidas a respeito do material coletado, observou-se que a cultura escolar do Colégio de Aplicação (UFS) foi marcada por diversas práticas educativas (jornadas esportivas e culturais, jogos escolares, atividades cívicas, excursões, passeios, demonstração de experimentos, encontro de formação de professores) e diferentes perfis de estudantes e de professorado. Portanto, o material levantado apresenta potencialidade importante para compreender essas diferentes configurações, os sentidos de práticas educativas e também a carreira profissional de professores(as) que colaboraram para a composição do "banco de histórias". Para a comunidade escolar e universitária como um todo, fomenta-se a importância da produção de fontes audiovisuais e da cultura da preservação e valorização da memória. Igualmente deve ser ressaltado o valor das memórias coletadas para a construção da identidade dos sujeitos e da instituição e as problemáticas relacionadas com "esquecimentos e silêncios" (POLLAK, 1989, 1992) da memória.

\section{REFERÊNCIAS}

ALBERTI, Verena. Manual de história oral. Rio de Janeiro: FGV, 2005.

ALVES, Eva Maria Siqueira. Entre papéis e lembranças: o Centro de Educação e Memória do Atheneu Sergipense e as contribuições para a História da Educação. Aracaju: Editora do Diário Oficial do Estado de Sergipe, 2015.

BELlOTTO, Heloísa Liberalli. Arquivos permanentes: tratamento documental. São Paulo: T. A. Queiroz, 1991. 
BOMENY, Helena Maria. A invenção do Patrimônio: continuidade e ruptura na constituição de uma política oficial de preservação no Brasil. Rio de janeiro: Ministério da Cultura/Instituto do Patrimônio Histórico e Artístico Nacional, 1995.

BOSI, Ecléa. Memória e sociedade: lembranças de velhos. São Paulo: Companhia das Letras, 1994.

BRASIL. Decreto-Lei $n^{0}$ 4.244, de 9 de abril de 1942. Lei orgânica do ensino secundário, 1942. Disponível em: <http://www2.camara.leg.br/legin/fed/declei/1940-1949/decreto-lei4244-9-abril-1942-414155-133712-pe.html>. Acesso em: 01 jul. 2018.

Decreto-Lei $\mathrm{n}^{0} 9.053$ de 12 de março de 1946. Determinava a obrigatoriedade do funcionamento de estabelecimentos de ensino, anexos às Faculdades de Filosofia, 1946.

Decreto-Lei no 269, de 28 de fevereiro de 1967. Autoriza o Poder Executivo a instituir a Fundação Universidade Federal de Sergipe e dá outras providências, 1967. Disponível em: $<$ http://www2.camara.leg.br/legin/fed/declei/1960-1969/decreto-lei-269-28-fevereiro-1967378094-norma-pe.html>. Acesso em: 01 jul. 2018.

CARDOSO, Maria Luiza. Pela preservação da memória e do patrimônio educacional militar: a criação do Centro de Memória do Ensino Militar na Universidade da Força Aérea. Revista Linhas, Florianópolis, v. 15, n. 28, p. 127-153, jan./jun. 2014.

CARVALHO, Maria Lucia Mendes de; RIBEIRO, Suzana Lopes Salgado (orgs.). História Oral na Educação: memórias e identidades. São Paulo: Centro Paula Souza, 2014.

CEMDAP. Centro de Memória, Documentação e Pesquisa do Colégio de Aplicação/UFS. Documentos da fundação do Ginásio de Aplicação (1959), 2016.

Centro de Memória, Documentação e Pesquisa do Colégio de Aplicação/UFS. Acervo fotográfico do Cemdap (figuras 1 a 3). 1959-1980.

Centro de Memória, Documentação e Pesquisa do Colégio de Aplicação/UFS. Acervo fotográfico (figuras 4 a 8). Projeto Composição de "banco de histórias" do Colégio de Aplicação (UFS). Combater "silêncios" e "esquecimentos" e preservar a memória institucional. 2017.

CONCEIÇÃO, Joaquim Tavares. Preservação e organização de documentos permanentes do Colégio de Aplicação da Universidade Federal de Sergipe. In: XI CONGRESSO LUSOBRASILEIRO DE HISTÓRIA DA EDUCAÇÃO. Comunicações individuais. Porto (Portugal). Anais... Universidade do Porto, 2016a. p. 1-11.

Centro de pesquisa, documentação e memória no espaço escolar e possibilidades para o ensino de história. Instrumento: R. Est. Pesq. Educ., Juiz de Fora, v. 18, n. 2, p. 211-219, jul./dez. 2016 b.

; NOGUEIRA, Maria Magna Menezes Correia Preservação e organização documental: O Centro de Pesquisa Documentação e Memória do Colégio de Aplicação - Cemdap (Dossiê "Os arquivos e a construção do conhecimento histórico"). Revista do Instituto Histórico e Geográfico de Sergipe, Aracaju, v. 1, n. 48. p. 63-73, ago. 2018. 
CENTRO DE MEMÓRIA, DOCUMENTAÇÃO E REFERÊNCIA ITAÚ CULTURAL. Centros de memória: manual básico para implantação. São Paulo: Itaú Cultural, 2013.

FERNANDES, Lincoln Christian. Memória ou esquecimento da educação escolar?: um itinerário de pesquisa de intervenção [livro eletrônico]. MS: Ed. UFGD, 2015. (Coleção Teses e Dissertações)

GUIMARÃES, Mariza Alves. Um olhar sobre a história da organização curricular da educação física no Colégio de Aplicação da Universidade Federal de Sergipe (1959-1996). 2016. 158 f. Dissertação (Mestrado em Educação) - Programa de Pós-Graduação em Educação, Universidade Federal de Sergipe, São Cristóvão, SE.

HORTA, Maria de Lourdes Pereiras; GRUNBERG, Evelina; MONTEIRO, Adriana Queiroz. Guia Básico de educação Patrimonial. Brasília: IPHAN/Museu Imperial, 1999.

LE GOFF, Jacques. História e memória. Trad. Bernardo Leitão. 2. ed. Campinas: Unicamp, 1992.

MARTIRES, José Genivaldo. "Flagrando a vida": trajetória de Lígia Pina - professora literata e acadêmica (1925-2014). 2016. 136 f. Dissertação (Mestrado em Educação) - Programa de Pós-Graduação em Educação, Universidade Federal de Sergipe, São Cristóvão, SE.

MENEZES, Maria Cristina. Escrever os documentos - construir o inventário - preservar a cultura material escolar. Revista Brasileira de História da Educação, Campinas-SP, v. 11, n. 1 (25), p. 93-116, jan./abr. 2011.

MEIHY, José Carlos Sebe B.; RIBEIRO, Suzana L. Salgado. Guia prático de história oral: para empresas, universidades, comunidades, famílias. São Paulo: Contexto, 2011.

2013.

; HOLANDA, Fabíola. História Oral. Como fazer, como pensar. São Paulo: Contexto,

NORA, Pierre. Entre memória e história. A problemática dos lugares (tradução: Yara Aun Khoury). Revista Projeto História, São Paulo, n. 10, p. 7-28, dez. 1993.

NUNES, Martha Suzana Cabral. Colégio de Aplicação da UFS: Memórias de um Ginásio de Ouro. São Cristóvão: UFS, 2012.

POLLAK, Michel. Memória e identidade social. Estudos Históricos, Rio de Janeiro, vol. 5, n. 10, p. 200-212, 1992. $15,1989$.

Memória, esquecimento, silêncio. Estudos Históricos, Rio de Janeiro, v. 2, n. 3, p. 3-

SIMSON, Olga Rodrigues de Moraes Von. Memória, cultura e poder na Sociedade do Esquecimento: o exemplo do centro de memória da Unicamp. In: FARIA FILHO, Luciano Mendes de (Org.). Arquivos, fontes e novas tecnologias: questões para a história da educação. Campinas: Autores Associados, 2000. p. 63-74. 
TESSITORE, Viviane. Como implantar centros de documentação. Como Fazer, v. 9. São Paulo: Arquivo Público do Estado; Imprensa Oficial do Estado, 2003.

THOMPSON, Paul. A Voz do Passado. História Oral. Rio de Janeiro: Paz e Terra, 1992.

ZAIA, Iomar Barbosa. O lugar do arquivo permanente dentro de um centro de memória escolar. Revista Brasileira de História da Educação, Campinas-SP, n. 10, p. 153-174, jul./dez. 2005. 